\title{
Exploring intentional use of a technological proxy, Turnitin, to enhance student academic literacy practices
}

\author{
Joanne Orlando, Jose Hanham, Jacqueline Ullman \\ Western Sydney University, Australia
}

Current pedagogical practices have seen the rapid spread of technological tools that carry out tasks on behalf of the learner; we use the term technological proxy to refer to these tools. A popular technological proxy used by students worldwide is a text-matching software called Turnitin. Turnitin alerts users to sections of an assignment that appear to match materials that exist in some other published or previously submitted form. This paper reports on a small case study that examined how university students use Turnitin and the implications its use has on their academic literacy practices. Drawing on theories of intentional learning, achievement goal orientation theory, and self-efficacy theory, we applied think-aloud protocols and focus groups to elicit data on students' interpretation and use of Turnitin feedback. Results show that the majority of students used the proxy with a performance goal orientation that focused on achieving a low similarity index. This dominating goal orientation is attributed to students' low self-efficacy for using the program, and the university's positioning of the program as a plagiarism tool. Hands-on experience with Turnitin contributed to a shift in using the program with intentionality.

\section{Background to the study}

One of the results of rapid technological advancements over the last few decades is an increasing reliance by human beings on technological tools, used to carry out tasks on their behalf. In occupations such as business, management, and accounting, many people use the software program Excel to carry out various kinds of numerical analyses on their behalf. Similarly, in aviation, many modern aircraft possess a range of flight management systems that carry out tasks on behalf of the flight crew, including altitude, speed, and navigation. From the perspective of social cognitive theory (Bandura, 2006), relationships in which one entity carries tasks on behalf of another can be classified as a proxy relationship.

In education, the use of online proxies is booming, and this is particularly evident with the array of digital technologies currently available that carry out some key components of academic writing on behalf of the learner (Chitez, Rapp, \& Kruse, 2015). For example, technological proxies have taken over some of the handson work associated with searching for relevant scholarly sources such as journal articles, conference papers, book chapters and patents (e.g., Google Scholar and ERIC). These search engines can streamline the process of locating information relevant to the research parameters of learners' written assignments. Pertinent to our current investigation is that students now can utilise a range of citation management tools, including Endnote and RefWorks, to assist them with referencing (Homol, 2014), which, for many students is a challenging aspect of academic writing (Head \& Eisenberg, 2010). These and other citation management tools automatically import citations from library databases, insert in-text citations, and format reference lists and bibliographies to match particular referencing styles such as APA or Harvard (Gilmour \& Cobus-Kuo, 2011).

Technological proxies present pedagogical dilemmas as they are designed to carry out some tasks on behalf of the learner. Research suggests that students in higher education still do not possess the necessary knowledge and skills to produce written output of high scholarly quality (Kellogg \& Whiteford, 2009). By using them, students may lose valuable opportunities to develop a deep understanding of referencing. Consequently, educators need to think carefully about what may be gained or lost in terms of learning when technological proxies are used in the production of student work.

Of interest to this study is the technological proxy Turnitin, a hugely popular text-matching detection software that is in use in over 15000 universities and secondary schools worldwide and growing (Turnitin, 2016). Turnitin is a relatively new tool available to students, and with the exception of a few studies (e.g., Dahl, 2007), 
there is minimal research which captures students' attitudes and behaviours to using Turnitin and the implications their use has on the preparation and submission of written assignments. While recent research has theorised about the motivational processes which underpin students' use of technological proxies (Hanham, Ullman, Orlando, \& McCormick, 2014), little empirical study has investigated students' use of Turnitin using this theoretical lens and the implications for their academic literacy. Accordingly, little is known about how motivational outcomes might be enhanced for intentional users of Turnitin and what their intention might look like in practice given Turnitin’s functionality.

This paper contributes to current understanding of the motivational outcomes of intentional learners in their uses of Turnitin. The authors examined how a cohort of university students interpreted and incorporated the feedback provided by Turnitin into their academic writing practices. We used think-aloud protocols (Ericsson, 2006; Fox, Ericsson, \& Best, 2011) alongside focus group data to investigate students' perspectives on the educational value of this software for their academic writing, and to better understand how their motivational perspectives influence their use. Using theories of intentional learning (Lee \& Hung, 2014; Sinatra \& Pintrich, 2003), achievement goals (Elliot, 2005), and self-efficacy (Bandura, 1997, 2012), we sought to understand how intentionality might influence the effectiveness of this technological proxy to support academic literacy.

\section{Turnitin as a technological proxy for academic literacy}

Although commonly referred to as a plagiarism detection (cloud-based) program, Turnitin does not detect plagiarism. Rather, it alerts the author to sections of text that appear to be either identical or close copies of online bibliographic material and previously submitted student assignments from educational institutions using Turnitin. The alerts, provided by Turnitin, include a quantitative measure, called the similarity index, which highlights the sections of the submitted written assignment which appear to match another source and provides a percentage match score. The score and highlighted section(s) need to be interpreted by the student as to whether they are instances of plagiarism or not. It is entirely possible that a person may have a high similarity index, despite having supplied the accurate in-text references, simply due to a large number of direct quotes from external sources and/or pro forma-type material in their document, which may be standard for students completing assessments.

As a technological proxy, Turnitin carries out critical tasks on behalf of the user through the explicit identification of matches and the generation of a similarity index. Although Turnitin may be interpreted by educational institutions and students as a punitive tool, the intended purpose of the feedback by Turnitin is to deepen the students' understanding of appropriate referencing practices and plagiarism and to use this to refine their assignments. Even though the potential to use this proxy to enhance learning is evident, students do not necessarily engage with Turnitin with this explicit goal in mind. In line with theories of intentional learning (Lee \& Hung, 2014; Sinatra \& Pintrich, 2003), for students to fully benefit from using Turnitin as a technological proxy, it is critical that they approach its use as an intentional learner.

\section{Intentional learning and achievement goals}

It has been theorised that students will vary in the deliberateness with which they use technological proxies to extend their learning (Hanham et al., 2014). Some students will make a conscious and deliberate decision to use a technological proxy, such as Turnitin, with the explicit goal of extending their knowledge. Such an approach is consistent with being an intentional learner. In educational literature, intentional learning (Bereiter \& Scardamalia, 1989; Lee \& Hung, 2014; Sinatra \& Pintrich, 2003) refers to an approach to acquiring knowledge that is goal directed and under the conscious control of the learner (Sinatra, 2000). According to Lee and Hung (2014), 'intentional learning is explicit when the learner acquires a specific set of target knowledge and when he or she is aware of and able to articulate what has been learned' (p. 3). Other students may simply use Turnitin without using the information provided by the program to think deeply about how the feedback from Turnitin can be used to extend their knowledge of academic writing practices and refine their work. Although it is possible that these students may in some way advance their knowledge of academic writing through using Turnitin, this outcome is likely to have lesser impact on their performance than a targeted strategy for improvement on the part of the student. 
Self-efficacy is a critical motivational component that underpins what people believe they can do in particular circumstances (Bandura, 1997). For specific academic tasks, such as essay writing and paragraph construction, people make judgements about their capability for successfully carrying out of these tasks. These judgements of one's perceived capabilities are known as self-efficacy beliefs (Bandura, 2012). People's self-efficacy beliefs are shaped by four factors: their interpretations of past mastery experiences, their observations of others' performances, verbal input from others, and their physiological and emotional states (Bandura, 2012). Selfefficacy is linked to the persistence and effort put into working through challenges. For example, when people have high self-efficacy for academic writing they are likely to expend effort advancing their skills and to persist when faced with difficulties that may occur when preparing academic writing assignments (Pintrich \& Schunk, 2002). Alternatively, those with weak self-efficacy for academic writing are likely to believe this task is beyond their capabilities, and therefore feel that they have limited control over their learning. Consequently, those with weak self-efficacy are likely to exert minimal effort or disengage from the task (Hanham et al., 2014).

Achievement goal orientations also serve as another important motivational component in intentionality in one's learning. According to Sparfeldt et al. (2015), 'achievement goals are related to the intention or motivational purpose to engage in particular tasks' (p. 170). A classic distinction in achievement goal theory is between mastery goals and performance goals (Dweck 1986; Nicholls 1984). Learners with a mastery goal orientation typically focus on building competence, developing skills, and mastering tasks. Those with a performance approach goal orientation tend to focus on demonstrating superior performance relative to the performances of others. With regard to a mastery-avoidance orientation, the focus is on avoiding being incompetent and a performance-avoidance orientation attention is directed towards not performing worse than others (Elliot, 2005). In general, approach goal orientations, particularly mastery-approach goals, are associated with a range of beneficial outcomes including deep level processing, intrinsic motivation, engagement, and metacognitive strategies, whereas avoidance orientation goals have been correlated with maladaptive outcomes such low engagement, surface level processing, and anxiety (for reviews see Moller \& Elliot, 2006; Senko, Hulleman, \& Harackiewicz, 2011). In the literature on intentional learning, scholars (e.g., Linnenbrink \& Pintrich, 2003) have theorised that intentional learners are likely to possess a mastery-goal orientation and have strong self-efficacy.

\section{Method}

The qualitative research presented in this paper had the dual purpose of understanding how students use and interpret Turnitin feedback, and exploring the ways in which their resultant academic writing may be impacted by an intentional approach to using this software. In total, eight students participated in the study. Five of those students volunteered to participate in phase 1 (think aloud), and all eight students volunteered to participate in phase 2 (focus groups). The following section explains the two-phase approach that was used to elicit student data. This is followed by a description of the data analysis, and the demographics of the sample.

The first phase of data collection employed think-aloud protocols (Ericsson, 2006; Ericsson \& Simon, 1993), where participants are asked to vocalise their thoughts as they simultaneously undertake a task (Trevors, FeyziBehnagh, Azevedo, \& Bouchet, 2016). One of the benefits of this approach is that the time period between one's actual experiences and reporting of those experiences is minimal, thus reducing memory and reporting bias (Lodge, Tripp, \& Harte, 2000). To facilitate the collection of verbal data, each participant created a short (less than 5 minutes) screen-capture video of their first exposure to a new set of Turnitin feedback on a recently submitted university essay. Students were encouraged to click through the Turnitin feedback online as they would normally, while concurrently verbalising the thought processes behind their interpretations of the feedback and their actions.

To assist students in the think-aloud process, prompts were provided to participants to explain their first set of actions/thoughts when they received their originality report; how they explored their similarity index and other feedback contained within the report in greater depth and, subsequently, and the aspects of their assignment that stood out to them as needing revision. We deliberately provided students with minimal guidance as to the 
aims and focus of the exploration. This method was chosen because it facilitated participants' exploration of their feedback through elements of personal importance to them (Cohen \& Crabtree, 2006) and the perceived value of the feedback for their academic literacy learning. Such think-aloud protocols with the technological proxy were deemed essential in order to expose students' underlying motivational processes throughout their interaction with the software package (Moos, 2014).

The think-aloud video-capture data was an important preliminary step towards the development of more structured follow-up focus group sessions (Cohen \& Crabtree, 2006) in the next phase of data collection. In phase 2, we arranged two semi-structured focus groups, each consisting of four students, organised according to availability. The purpose of this data collection method was to extend on the key themes developed from the analysis of students' screen-capture videos. These themes included scholarly ethics, how the university positions Turnitin, and the development of academic literacy. This method enabled for both targeted exploration and between-student conversation regarding perceptions of the utility and value of engaging with Turnitin.

\section{Data analysis}

Our aim in this study was to explore how students' motivational processes and approaches, including the concept of intentionality as both a mindset and a set of resultant actions, might be reflected in and constitutive of their mandated use of Turnitin as a technological proxy in the academic writing process. Our exploration of the various data artefacts (videos and transcriptions of focus group conversations) involved following several phases advocated by Braun and Clarke (2006). As a first phase, we independently viewed the videos and read the transcripts. This was repeated several times, with the authors actively searching for meaning and patterns in the data.

Our analysis was informed by the understanding that intentional learners are likely to exhibit the following motivational attributes: an understanding of what Turnitin can do on their behalf, and self-efficacy in their academic writing and/or using Turnitin as a proxy; and emphasis on improving one's skill in academic writing. Conversely, as Turnitin is framed as a surveillance/punitive tool, there is an associated potential for distrust and disengagement alongside the difficulties with academic writing experienced by many university students. We were also interested in students who displayed the opposite of the above criteria: a superficial approach to using Turnitin; low self-efficacy for using Turnitin; lack of perseverance in the face of difficulty; and a de-emphasis on self-improvement or learning.

With this analytical framework, each author carried out initial descriptive coding of the entire dataset, creating a set of codes which were then collapsed thematically (Saldana, 2009. Codes were compared across the three authors for intercoder reliability (Creswell, 2009), with authors found to be in agreement on thematic organisation. For the initial cross-checking, there was $80 \%$ agreement in the themes identified (Viera \& Garrett, 2005). The final themes presented represent a reconciled position facilitated by discussion between the three authors, assessing the extent to which a potential theme was informative in terms of the aims of the study. A working title and brief descriptor was allocated to each theme. It is important to note that self-efficacy beliefs and goal orientations are usually measured using empirically validated survey instruments. Because of the qualitative focus and small sample size, we made inferences about the participants' self-efficacy beliefs and goal orientations based on their verbalisations.

\section{Sample}

Given the project aims and the subsequent methodological approach as outlined above, the study necessitated rich data exploration, drilling down using smaller numbers of cases(students). Recruitment involved accessing a purposive sample of students enrolled in a unit of study within the School of Education, which required assessments to be submitted using Turnitin during in a 2-week period prior to the scheduled data collection. At the conclusion of a lecture in each of these identified units of study, one of the authors provided a brief outline of the research and project contact details. Of the eight students who volunteered to participate in the study, three were enrolled in an undergraduate degree and five in a postgraduate degree. Reflecting the demographics of Western Sydney University, all the participating students had English as a second or third language. The 
students were aged 20-28 years, and the length of time they had been using Turnitin ranged from 6 months to 4 years. This diversity facilitated a range of views and experiences with scholarly writing and the resources students may use to facilitate and enhance the quality of their assignments. The small sample of university students from a single tertiary institution reduces the generalisability of the study; however, this sample supported the production of important insights into the contribution of intentionality, which are detailed below. In particular, it supported a deep understanding of the views and experiences of the students in the ways they engaged with and learnt from their uses of Turnitin. University ethics approval was given to collect and report on data.

\section{Findings}

In the sections that follow, we present our organisation of key findings, identified through our theoretically informed analysis. The first section presents an examination of students' verbalisations and actions for evidence of intentionality when using Turnitin. The second section presents themes which arose from the focus group data. Differences in students' motivational orientations (performance vs. mastery) were evident and these appeared to have implications for their long-term use and valuing of Turnitin for the development of their academic writing.

\section{Turnitin use for assignment feedback}

Our analysis of the audio and visual elements of the video footage facilitated the identification of a pattern of three sequential steps that each participant progressed through when engaging with the originality report generated by Turnitin. These steps are outlined in Table 1; importantly, these provide insight into the students' motivations for using Turnitin as a proxy and the ways they acted on the feedback in relation to their assignment and the learning that they took from this process.

The students' movement between steps 2 and 3 was critical for our analysis as it illustrated their varying motivations for using Turnitin as a proxy. Critical to the differences displayed was how they engaged with the similarity index and the other information the report offered. Students 3 and 5 focused on the similarity index and the need to reduce the number. In contrast, from the outset of their engagement with the Turnitin feedback, students 1, 2 and 4 viewed the originality report as comprised of a set of components, one of which was the similarity index. When viewed this way, these students then interpreted which components needed addressing in light of the feedback (i.e., reviewing match overview statistics or the degree to which specific sentences were highlighted). The breaking down of their originality report in this manner appeared to allow for a more nuanced understanding of their own academic literacy capabilities and their similarity index score.

Students' particular path of engagement with the originality report in step 2 was then carried through to step 3 , informing their perceived next steps in terms of revisions and additional research or readings. Students 3 and 5 focused simply on reducing their overall similarity index score. Students 2 and 4 aimed to reduce the similarity index but in a way which also aligned with the particular requirements of their subject. Student 1 , however, aimed to reduce her score in a way that also ensured that it matched the requirements of the subject but that also was of a high scholarly standard. Interestingly, each of these three students $(1,3,5)$ also pointed to the need to use other sources to assist them in improving their writing. While they had confidence in Turnitin, they also realised that multiple sources are best needed to improve their academic literacy. 
Table 1

Video-recorded actions and verbalisations from video data when using Turnitin

\begin{tabular}{|c|c|c|c|c|c|}
\hline & Student 1 & Student 2 & Student 3 & Student 4 & Student 5 \\
\hline $\begin{array}{l}\text { Step 1: } \\
\text { Checked } \\
\text { similarity } \\
\text { index }\end{array}$ & $\begin{array}{l}\text { Looked at score } \\
\text { for similarity } \\
\text { index }\end{array}$ & $\begin{array}{l}\text { Looked at score } \\
\text { for similarity } \\
\text { index }\end{array}$ & $\begin{array}{l}\text { Looked at score } \\
\text { for similarity } \\
\text { index }\end{array}$ & $\begin{array}{l}\text { Looked at score } \\
\text { for similarity } \\
\text { index }\end{array}$ & $\begin{array}{l}\text { Looked at score } \\
\text { for similarity } \\
\text { index }\end{array}$ \\
\hline $\begin{array}{l}\text { Step 2: } \\
\text { Judgements } \\
\text { about the } \\
\text { significant } \\
\text { matches } \\
\text { Turnitin } \\
\text { identified }\end{array}$ & $\begin{array}{l}\text { Sentences } \\
\text { greater than } \\
70 \% \text { match } \\
\text { were } \\
\text { considered } \\
\text { significant } \\
\text { matches }\end{array}$ & $\begin{array}{l}\text { Higher } \\
\text { percentage } \\
\text { matches in } \\
\text { match overview } \\
\text { column used to } \\
\text { identify } \\
\text { significant } \\
\text { matches }\end{array}$ & $\begin{array}{l}\text { Used } \\
\text { highlighted } \\
\text { blocks of } \\
\text { colour in body } \\
\text { of assignment } \\
\text { to identify } \\
\text { significant } \\
\text { matches }\end{array}$ & $\begin{array}{l}\text { Used } \\
\text { highlighted } \\
\text { blocks of } \\
\text { colour in body } \\
\text { of assignment } \\
\text { to identify } \\
\text { significant } \\
\text { matches }\end{array}$ & $\begin{array}{l}\text { Higher } \\
\text { percentage } \\
\text { matches in } \\
\text { match overview } \\
\text { column used to } \\
\text { identify } \\
\text { significant } \\
\text { matches }\end{array}$ \\
\hline $\begin{array}{l}\text { Step 3: } \\
\text { Intended } \\
\text { actions }\end{array}$ & $\begin{array}{l}\text { Modifications } \\
\text { based on } \\
\text { student's } \\
\text { perceptions of } \\
\text { good academic } \\
\text { writing }\end{array}$ & $\begin{array}{l}\text { Modifications } \\
\text { to reduce } \\
\text { similarity index } \\
\text { and to address } \\
\text { the perceived } \\
\text { needs of the } \\
\text { tutor and } \\
\text { subject } \\
\text { requirements }\end{array}$ & $\begin{array}{l}\text { Modifications } \\
\text { based on } \\
\text { reducing } \\
\text { overall } \\
\text { similarity index } \\
\text { to less than } \\
10 \%\end{array}$ & $\begin{array}{l}\text { Modifications } \\
\text { to reduce } \\
\text { similarity index } \\
\text { and to address } \\
\text { the perceived } \\
\text { needs of the } \\
\text { tutor and } \\
\text { subject } \\
\text { requirements }\end{array}$ & $\begin{array}{l}\text { Modifications } \\
\text { based on } \\
\text { reducing } \\
\text { overall } \\
\text { similarity index } \\
\text { to less than } \\
15 \%\end{array}$ \\
\hline
\end{tabular}

A comparison of the students' approaches to these steps suggests that only one of the five (student 1) used the feedback as an intentional learner, working to ensure that her assignment was of a good scholarly standard. Intentional learners are goal directed, with the intention to learn, and learn deeply. While student 1 acknowledged the similarity index, her focus extended beyond the score to ensure her work was on high quality academic work according to more extensive measurements.

\section{Big-picture valuing and positioning of Turnitin as a proxy}

Most students demonstrated a performance goal orientation in their use of the program, using it to gain proof of the quality of their assessment through a low similarity index. These students prioritised not getting "picked up” for plagiarism. They displayed mechanistic uses of the software, using it primarily to modify their writing in ways that would improve their own originality, as evidenced via a low similarity index:

Even if I got anything, if it's yellow [e.g., marked as duplicate material], then I would change it, I would go back and delete.

Like once you get that percentage back you kind of feel happy when you've (got) a low percentage.

I remember one assignment I got $40 \%$ for. I think I screamed at my mum because I was just like, how? I went and changed all of it.

The goal orientation of the students above was different to those students who used the program with intentionality, prioritising using feedback as a tool to extend their knowledge of academic writing. Perhaps unsurprisingly, students who appeared to exhibit a performance goal framing did not highlight ways in which Turnitin may be used to enhance writing ability or overall submission quality. 
Various external messages about the role and importance of Turnitin that were communicated to students positioned the program as a plagiarism tool, which encouraged a performance goal orientation. These messages stemmed from the general discourses related to learning either at their university, or within their chosen discipline, to more specific, localised, contextual factors such as advice from specific tutors; the assignment marking criteria as outlined in their assessment documentation; and the referencing requirements of the university. Each of these factors emphasised the message that assignment quality is measured by low Turnitin scores.

One standout commonality across all participants was their sense that during the early stages of their undergraduate degree, academic and support staff (including library staff) formally introduced Turnitin as a plagiarism detection tool. During both focus groups, participants shared stories about these introductory explanations, outlining how staff focused on the technical steps of assignment submission through Turnitin, including how students should read their originality report. In these excerpts, a noteworthy feature was the view that higher scores equated with a poor-performing assessment task. As communicated by participants, the tutors who marked their assignments reinforced this punitive focus. As the excerpt below illustrates, students appeared to develop an emotive response to Turnitin during these early semesters of university, due to a conflation between essay success and university expectations of the use of the software:

There's this hype from our tutors, like from the first week into uni, we get this constant reminder, what Turnitin is, and [staff insinuating] "We've got these eyes on you that, if you plagiarise ... the higher the percentage, the more - the likelihood that you're gonna actually fail.” But rather now, at my third year, I realise that they don't even comment on it, the teachers.

Student anxiety such as that expressed by the student above might have been alleviated, and students could potentially have felt more empowered in the quality and commitment to their work, had Turnitin been explicitly framed as a learning tool. Focus groups suggested that the positioning of Turnitin by their university remained somewhat consistent as a plagiarism check throughout their course of study. However, students' knowledge of, and associated mastery experiences with, academic literacy and university life appeared to influence their own interpretation of Turnitin feedback.

A second factor that influenced participants' goals in their use of Turnitin was their knowledge of academic literacy. Students who stated that their academic writing or language skills were weak particularly valued the similarity index as an outcome performance measure:

I am bilingual and so I have to start assignments a lot earlier than everyone else because it takes me so long. Turnitin forces me to make changes to sentences, think of other ways to write a sentence - which is good, because I wouldn’t do it otherwise.

My English .... Turnitin would help. It forced me to change. I said to myself before that I'm not able to change it [the highlighted sentence] but I found a way to do it, because I had to. No matter if I spent one hour to change it, I had to change it otherwise I thought I wouldn't pass. Turnitin it kind of forced me to change it. It gave me these new skills to paraphrase.

As is indicated by the two students quoted below, as knowledge of academic literacy developed over the duration of their degree(s), students found the similarity index of Turnitin to be less relevant to their overall assignment quality:

The first year, I didn't know how to reference properly, but I asked the teacher to help me and he did. And since then, I've never worried about the percentage.

It helps to detect plagiarism, but it doesn't really help the quality of the essay.

Mastery experiences are the strongest predictor of self-efficacy (Bandura, 1997). It is likely that these students, having acquired mastery experiences in academic writing and Turnitin when preparing writing assignments, 
are likely to have a more nuanced understanding of their own writing capabilities and the limitations of Turnitin. Indeed, we would expect self-efficacious writers to afford more weight to their own writing capabilities and be less concerned with the output provided Turnitin. Such a positioning is evident through the quote of the student below who spoke confidently about a reclaiming of "power" from Turnitin, reframing herself as an active user of the technological proxy, rather than a passive recipient of its "verdict" via the similarity index:

I take the power. Because if I know - if I’ve referenced and I haven't, you know, intentionally, you know, plagiarised it, I don’t worry about it. Because I know, even if the teacher picks it up and asks me ... I'll tell him, no, because this is my draft; this is where my information's from, I did not use it [others' sources without referencing]. I've got the power.

As students reflected on becoming more familiar with the capacities and limitations of Turnitin and developed greater confidence in their writing, they reframed the similarity index as just one piece of information about their work, one which was only indirectly linked to the quality of their writing. Consequently, these students could be more conscious and deliberate in how much weight they would afford to the similarity index in making decisions and could be more intentional in how they utilised the information provided by Turnitin. As these students became more experienced and knowledgeable about the capacities and limitations of Turnitin, they could be more intentional in how much emphasis they placed on the feedback provided by the program. In this case, students communicated that they were willing to accept and keep a higher similarity index.

\section{Intentional learners}

Despite the university's positioning of Turnitin which, we argue, encouraged a performance goal-oriented approach to using Turnitin, a smaller number of student participants demonstrated intentionality in their uses of Turnitin and positioned it as an educative tool. The quote below is taken from one such student. Her explanation suggests that Turnitin feedback encourages her to improve the quality of her work based on the feedback given, and assists her with revisions as she works to ensure that her ideas and original arguments are clearly expressed. This student's goal was clear: externally informed, yet original, academic writing expression, as evidenced by a desire to reframe others' work in her own way:

I go back and I rework it in such a way that, you know, it gets across what I want to say without having ... to be additionally referenced.

It is important to state that these students did not always demonstrate intentionality in their use of Turnitin; on some occasions, they described what appeared to be a shift to a performance goal orientation. Students' retrospective discussions indicated that some students had experienced a short-term shift from intentional to performance goal oriented; for example, a time management issue of running late with assignment preparation resulted in some students reverting back to using Turnitin simplistically, with just a quick check of their similarity index as an indication of any dramatic oversights. For other students, there was an important and continuing developmental trajectory of becoming less reliant on Turnitin as their own command of academic literacy developed. As the quote below illustrates, becoming less reliant on Turnitin was associated with students using the tool with greater intentionality, as an indicator of gaps in their own knowledge and a stimulus for mastery learning experiences:

It [Turnitin] made me detect that I had a - a paraphrasing problem and that's what led me to improve.

Bandura (1997) posited that self-efficacious learners organise and recruit the necessary tools to help them achieve their goals. This was evident in the ways they had gathered a repertoire of tools and knowledge to assist their academic literacy; Turnitin was just one of them. As the quote below shows, they actively and intentionally selected which tools they needed at particular times to support their learning:

I've noticed that my writing has become way better since when I first started. But I'm not entirely sure if it was because of Turnitin. I think because of other resources as well, and I think practising 
as well, and Turnitin was like a little tool on the side, they helped me with that little problem that I had.

Students' approach to engaging with Turnitin in intentional ways appeared to also be attributed to other factors such as greater familiarity with the interface design, with technology, or the university assignment process. Explanations by students 1, 2 and 4 (as per Table 1), who were self-efficacious intentional learners, suggest that they developed a more nuanced understanding of Turnitin and became more cognisant of the fallibility of the program over time. They also developed a more critical reading of their similarity index. As they discussed their interaction with the software, they highlighted an awareness that a high similarity index was not necessarily an indicator of plagiarism, nor of a low-quality assignment. This informed understanding appeared to parallel a growing self-efficacy in the students' written expression and ability to reference appropriately:

I've realised that the teachers want the actual [quotes] - they want, like pure example, explanations, and they really want your examples and evidence that you understand the work. So now I'm like, no, I don’t really care about the percentage.

Students who appeared to be more self-efficacious were also more familiar with the intricacies of Turnitin and academic literacy. These students appeared to be more deliberate and nuanced in their interactions with and interpretations of the software. They critiqued the process, simultaneously realising that their similarity index is a number that has meaning, but requires interpretation. These students appeared to move beyond having a grand emotive response to the number:

And when I saw that 60 per cent I was like shocked, and panicked a little bit. I mean it didn't, it didn't send alarm bells anymore. So I kind of understand it. That's how Turnitin's percentage works - it's not just based on the content but also on the formats and layouts.

As the students gained greater experience with the software and became comfortable exploring the interface, some also taught themselves how to manipulate the similarity index. Through this process, students appeared to become more consciously aware of the fallibility of the application and therefore it usefulness (or lack thereof) to them as a technological proxy which could be used to support their academic literacy development:

You, can you work the filter, that's my method. So yeah you have a lower score if you use the filter ... Yeah, it gives you that relief ... It's like cheating but not cheating.

Students strategically leveraged their experience of Turnitin and a greater command of academic literacy, to use the resource more strategically; that is, a shift from simply reacting to the feedback without question, to having a more sophisticated interpretation of feedback as a proxy. If some academic writing needs were not met through Turnitin then they would seek out other proxies or resources to supplement the feedback provided by Turnitin. The repertoire they developed often included a blend of technology resources (such as select websites and apps) with non-technology resources (such as asking a friend to read their work, joining writing groups).

\section{Discussion}

Three of the eight study participants appeared to exhibit a performance goal orientation. In line with the literature discussed earlier (Dweck 1986; Nicholls 1984), the external factors that motivated these participants were those of social comparison, they focused on outranking their peers in terms of score, and in terms of character (i.e., being more ethical than others in their approach to assignment writing). A good similarity index from Turnitin was a prime external motivator for these students. Reliance on external motivation factors encouraged more punitive use of the program that simply aimed to reduce the score. Students wanted external affirmation that what they were doing was both academically and ethically correct and used scores and rules of practice as benchmarks to support this. 
Students who demonstrated an intentional approach to their use of Turnitin could see the added value for their goal of self-improvement in writing. These students who appeared to focus on internal motivators tended to express more critical use of Turnitin, contextualising its use and its value within their understandings what is needed for quality scholarly work. Such thinking is in line with a mastery goal approach to learning.

A key question underpinning this study was whether students' use of a technological proxy such as Turnitin would come at the expense of developing a deep understanding of referencing and scholarly writing. Relevant to this is that all the students discussed growth in their capability for academic writing. In some students, this was expressed as a shift from reliance on external factors to internal factors. This shift reflected a greater level of self-efficacy (Bandura, 2012) in academic writing. Their increased awareness of the fallibility of Turnitin was also an example of this. As some students became more self-efficacious in their academic writing, they identified the need to learn from a range of sources. They demonstrated a stronger sense of belief in their academic writing ability and were more open to improving it. They identified where the gaps were in their knowledge, what they needed to do to address them and were aware when they had acquired the necessary knowledge. These are attributes of intentional learners. The more knowledge one acquires as an intentional learner, the more likely they are to be aware of the necessary resources to obtain their goal.

The students discussed that their growth in academic literacy occurred informally, without specific interventions that related to Turnitin. It appears that time and hands-on experience with Turnitin play a key role in whether and how it is used with intentionality. Primers would further enhance the shift from a non-mastery to mastery approach. Making the shift to using this technological proxy in a mastery way requires that learners perceive that they have the capabilities (self-efficacy) to take advantage of all the features of Turnitin (Hanham et al., 2014). This may happen organically through cumulative experiences with writing assignments and with using Turnitin as part of that process. It can also be supplemented and enhanced through explicit pedagogical strategies that aim to develop a deep understanding of the Turnitin program, how it works, the value of the various functions, how they can be manipulated and how they can be used to enhance knowledge of referencing and academic writing. Learners need to perceive that the program itself possesses the capabilities (proxy efficacy) to help them improve their academic literacy skills.

\section{Conclusion}

The study shows that a technological proxy, Turnitin, can be used by learners in strategic ways that facilitate a deeper knowledge and capacity for academic writing practices. Students who demonstrated intentionality in their use of Turnitin engaged with the program in a nuanced way, which supported the self-identification of gaps in their academic literacy knowledge and skills. They then used an array of resources to develop their assignment and more broadly their own learning in this area.

A greater understanding of the program also contributed to a shift in how the students who had a performance goal approached their use of the program. While they remained fixed on responding to external measures of performance, they demonstrated more control in their academic writing. This was evident in how they critiqued the usefulness of Turnitin as a proxy. Unlike the intentional users of Turnitin, however, they did not necessarily seek out other resources to further enhance their learning.

While the choice of the technological proxy is crucial, equally important is the framing of the technological proxy, as this will directly translate to how students will use it. Framing includes the ways in which the technological proxy is introduced and explained to students, the way it is positioned in policy documents, and how it is used in teaching and learning. If the communication, policy, and pedagogical practice are negative and punitive, then student use of the proxy will reflect such a framing. Based on this study, some of the potential consequences are increased anxiety, surface learning, and maladaptive approaches to assessment. On the other hand, framing the technological proxy in an empowering way can lead to deep learning, enable students to exercise control, and to adopt more adaptive approaches to assessments. The experiences students accumulate at university can counter-balance some of the negative framing; however, it is important to emphasise that there 
is a loss of opportunity in the early stages of their university life to use technological proxies as intentional learners.

\section{Limitations and directions for future research}

Before summarising the key contributions of the study, it must be acknowledged that this study had several limitations that minimise the generalisability of the findings. First, the analysis was based on data collected from a small sample of university studies from a single tertiary institution. Future research should involve a larger number of randomly selected students from a broader range of disciplines and university settings in order to provide more generalisable findings. Second, the participants were all non-native English speakers. While this element of demographic difference is pertinent to research examining academic writing development, we were not able to explore this due to the small sample size. A larger sample size would support such sub-cohort investigations. Third, we made inferences about the participants' self-efficacy beliefs and goal orientations based on their verbalisations. Self-efficacy beliefs and goal orientations are usually measured using empirically validated survey instruments. Future research with a larger sample size would support the use of survey research using pre-existing scale measures of these constructs.

\section{Recommendations}

Although this is a small-scale study, we tentatively offer some suggestions to universities, teachers, and students concerning the role of Turnitin in the development of students' academic writing skills. Encouragement of universities to frame plagiarism detection software programs, such as Turntin, as punitive tools, may encourage students to adopt goal orientations (i.e., performance goals) that are associated with surface approaches to learning, rather than deep learning (Senko et al., 2011). It perhaps would be more fruitful for universities to shift their focus from a punitive angle to one that positions Turnitin as a learning tool that can be used to enhance academic writing skills. From the participant responses, it appears that acquiring experience in academic writing and Turnitin was associated with increases in self-efficacy for academic writing and using Turnitin. Reframing Turnitin from a punitive instrument to a learning tool may speed up the process by which students' self-efficacy beliefs are enhanced. This is important as we know that those with weak self-efficacy are more likely to give up when faced with obstacles and setbacks than those with strong self-efficacy beliefs (Bandura, 1997). For students who enter university with pre-existing reservations about their capabilities for meeting the demands of university, including academic writing, it is desirable that they develop strong perceptions of their academic capabilities relatively early in their course of study. More broadly, this strategic process can be applied when introducing other technological proxies into the educational environment for students to use. The focus should ideally be on how it can be used to support and enhance learning rather than surveillance.

Universities should be encouraged to provide training that will allow educators to develop not only a deep understanding of the functions of Turnitin, but also how this software program, and similar programs, can be used to improve students' academic writing skills. Based on social cognitive theory (Bandura, 1997), with which self-efficacy is located, there are several strategies that can be adopted to improve students' perceived capabilities for using Turnitin as tool for improving academic writing skills. Modelling, that is, learning from observing the performances of peers and/or experts, is an important source of self-efficacy (Bandura, 1997; Klassen, 2004). Teachers may use group strategies, such as mixed-ability grouping, when students with limited experience of or confidence in using Turnitin may be placed with students with more mastery experiences in using Turntin in their academic writing. Verbal persuasion is another source by which people base their selfefficacy beliefs. It may be advisable for teachers to encourage students to view Turnitin as a learning tool rather than as a surveillance device. Indeed, this may alleviate anxiety around academic writing assignments and Turnitin. Notably, one's physiological and emotional state is also a source of self-efficacy. Eliminating or reducing anxiety around Turnitin could have positive impacts on students' self-efficacy beliefs. 


\section{References}

Bandura, A. (1997). Self-efficacy: The exercise of control. New York NY: Freeman.

Bandura, A. (2006). Toward a psychology of human agency. Perspectives on Psychological Science, 1, 164180. http://dx.doi.org/10.1111/j.1745-6916.2006.00011.x

Bandura, A. (2012). On the functional properties of perceived self-efficacy revisited. Journal of Management, 38(1), 9-44. https://doi.org/10.1177/0149206311410606

Bereiter, C., \& Scardamalia, M. (1989). Intentional learning as a goal of instruction. In L. B. Resnick (Ed.), Knowing, learning, and instruction: Essays in honor of Robert Glaser (pp. 361-392). Hillsdale, NJ: Erlbaum.

Braun. V., \& Clarke, V. (2006). Using thematic analysis in psychology. Qualitative Research in Psychology, 3(2), 77-101. https://doi.org/10.1191/1478088706qp063oa

Chitez, M., Rapp, C., \& Kruse, O. (2015). Corpus-supported academic writing: How can technology help? In F. Helm, L. Bradley, M. Guarda, \& S. Thouseny (Eds), Critical CALL-Proceedings of the 2015 EUROCALL Conference (pp. 125-132). Dublin: Research Publishing Net. https://doi.org/10.14705/rpnet.2015.000321

Cohen D., \& Crabtree, B. (2006). Qualitative research guidelines project. Retrieved from http://www.qualres.org/

Creswell, J. W. (2009). Research design: Quantitative, qualitative and mixed methods approaches (4th ed.) New York, NY: Sage.

Dahl, S. (2007). Turnitin: The student perspective on using plagiarism software. Active Learning in Higher Education, 8(2), 173-191. https://doi.org/10.1177/1469787407074110

Dweck, C. (1986). Motivational processes affecting learning. American Psychologist, 41(10), 1040-1048.

Elliot, A. J. (2005). A conceptual history of the achievement goal construct. In A. J. Elliot \& C. S. Dweck (Eds.), Handbook of competence and motivation (pp. 52-72). New York, NY: Guildford.

Ericsson, K. A. (2006). Protocol analysis and expert thought: Concurrent verbalizations of thinking during experts' performance on representative tasks. In K. A. Ericsson, N. Charness, P. J. Feltovich, \& R. Hoffman (Eds.), Handbook of expertise and expert performance (pp. 223-241). New York, NY: Cambridge University Press

Ericsson, K., \& Simon, H. (1993). Protocol analysis: Verbal reports as data (2nd ed.). Boston, MA: MIT Press.

Fox, M. C., Ericsson, K. A., \& Best, R. (2011). Do procedures for verbal reporting of thinking have to be reactive? A meta-analysis and recommendations for best reporting methods. Psychological Bulletin, 137(2), 316-344. https://doi.org/10.1037/a0021663

Gilmour, R., \& Cobus-Kuo, L. (2011). Reference management software: A comparative analysis of four products. Issues in Science and Technology Librarianship, 66, 63-75. https://doi.org/10.5062/F4Z60KZF

Hanham, J., Ullman, J., Orlando, J., \& McCormick, J. (2014). Intentional learning with technological proxies: Goal orientations and efficacy beliefs. Australian Journal of Education, 58(1), 36-49. https://doi.org/10.1177/0004944113517831

Head, A. J., \& Eisenberg, M.B. (2010). Truth be told: How college students evaluate and use information in the digital age. Retrieved from http://www.projectinfolit.org/uploads/2/7/5/4/27541717/pil_fall2010_survey_fullreport1.pdf

Homol, L. (2014). Web-based citation management tools: Comparing the accuracy of their electronic journal citations. The Journal of Academic Librarianship, 40, 552-557. https://doi.org/10.1016/j.acalib.2014.09.011

Kellogg, R. T., \& Whiteford, A. P. (2009). Training advanced writing skills: The case for deliberate practice. Educational Psychologist, 44, 250-266. https://doi.org/10.1080/00461520903213600

Klassen, R. (2004). A cross-cultural investigation of the efficacy beliefs of South Asian immigrant and Anglo Canadian nonimmigrant early adolescents. Journal of Educational Psychology, 96, 731-742. https://doi.org/10.1037/0022-0663.96.4.731

Lee, C., \& Hung, W. (2014) From the guest editors: Fostering intentional learning with technologies. Australian Journal of Education, 58, 3-8. https://doi.org/10.1177/0004944113517795

Linnenbrink, E. A., \& Pintrich, P. R. (2003). Achievement goals and intentional conceptual change. In G. M. Sinatra \& P. R. Pintrich (Eds.), Intentional conceptual change (pp. 347-374). Mahwah, NJ: Erlbaum. 
Lodge, J., Tripp, G., \& Harte, D.K. (2000). Think-aloud, thought-listing, and video-mediated recall procedures in the assessment of children's self-talk. Cognitive Therapy and Research, 24(4), 399418. https://doi.org/10.1023/A:1005575618941

Moller, A. C., \& Elliot, A. J. (2006). The $2 \times 2$ achievement goal framework: An overview of empirical research. In A. V. Mitel (Ed.), Focus on educational psychology (pp. 307-326). Hauppauge, NY: Nova Science Publishers.

Moos, D.C. (2014). Setting the stage for metacognition during hypermedia learning: What motivation constructs matter? Computers \& Education, 70, 128-137. https://doi.org/10.1016/j.compedu.2013.08.014

Nicholls, J. (1984). Conceptions of ability and achievement motivation. In R. Ames \& C. Ames (Eds.), Research on motivation in education: Vol. I. Student motivation (pp. 39-73). New York, NY: Academic Press.

Pintrich, P. R., \& Schunk, D. H. (2002). Motivation in education: Theory, research, and applications (2nd ed). Columbus, OH: Merrill-Prentice Hall.

Saldana, J. (2009). The coding manual for qualitative researchers. Phoenix, AZ: Sage.

Senko, C., Hulleman, C. S., \& Harackiewicz, J. M. (2011). Achievement goal theory at the crossroads. Old controversies, current challenges, and new directions. Educational Psychologist, 46(1), 26-47. https://doi.org/10.1080/00461520.2011.538646

Sinatra, G. M. (2000, April). From passive to active to intentional: Changing conceptions of the learner. What does it mean to be an intentional learner? Alternative perspectives. Symposium presented at the American Educational Research Association Annual Meeting, New Orleans, LA.

Sinatra, G. M., \& Pintrich, P. R. (2003). The role of intentions in conceptual change learning. In G. M. Sinatra \& P. R. Pintrich (Eds.), Intentional conceptual change (pp. 1-18). Mahwah, NJ: Erlbaum.

Sparfeldt, J. R., Brunnemann, N., Wirthwein, L., Buch, S. R., Schult, J., \& Rost, D. H. (2015). General versus specific achievement goals: A re-examination. Learning and Individual Differences, 43, 170177. https://doi.org/10.1016/j.lindif.2015.08.022

Trevors, G., Feyzi-Behnagh, Azevedo, R., \& Bouchet, F (2016). Self-regulated learning processes vary as a function of epistemic beliefs and contexts: Mixed method evidence from eye tracking and concurrent and retrospective reports. Learning and Instruction, 42, 31-46. https://doi.org/10.1016/j.learninstruc.2015.11.003

Turnitin. (2017). About us. Retrieved from http://turnitin.com/en_us/about-us/our-company

Viera, A., \& Garrett, J. (2005). Understanding interobserver agreement: The Kappa statistic. Family Medicine, 37(5), 360-363.

Corresponding author: Joanne Orlando, j.orlando@westernsydney.edu.au

Australasian Journal of Educational Technology @ 2018.

Please cite as: Orlando, J., Hanham, J., \& Ullman. J. (2018). Exploring intentional use of a technological proxy, Turnitin, to enhance student academic literacy practices. Australasian Journal of Educational Technology, 34(4), 44-56. https://doi.org/10.14742/ajet.3575 